\title{
Landing Gear Aerodynamic Noise Prediction Using Building-Cube Method
}

\author{
Daisuke Sasaki, Deguchi Akihito, Hiroshi Onda, and Kazuhiro Nakahashi
}

Department of Aerospace Engineering, Tohoku University, Aoba 6-6-01, Sendai 980-8579, Japan

Correspondence should be addressed to Daisuke Sasaki, sasaki@ad.mech.tohoku.ac.jp

Received 9 December 2011; Accepted 19 January 2012

Academic Editor: Guan Heng Yeoh

Copyright () 2012 Daisuke Sasaki et al. This is an open access article distributed under the Creative Commons Attribution License, which permits unrestricted use, distribution, and reproduction in any medium, provided the original work is properly cited.

Landing gear noise prediction method is developed using Building-Cube Method (BCM). The BCM is a multiblock-structured Cartesian mesh flow solver, which aims to enable practical large-scale computation. The computational domain is composed of assemblage of various sizes of building blocks where small blocks are used to capture flow features in detail. Because of Cartesianbased mesh, easy and fast mesh generation for complicated geometries is achieved. The airframe noise is predicted through the coupling of incompressible Navier-Stokes flow solver and the aeroacoustic analogy-based Curle's equation. In this paper, Curle's equation in noncompact form is introduced to predict the acoustic sound from an object in flow. This approach is applied to JAXA Landing gear Evaluation Geometry model to investigate the influence of the detail components to flows and aerodynamic noises. The position of torque link and the wheel cap geometry are changed to discuss the influence. The present method showed good agreement with the preceding experimental result and proved that difference of the complicated components to far field noise was estimated. The result also shows that the torque link position highly affects the flow acceleration at the axle region between two wheels, which causes the change in SPL at observation point.

\section{Introduction}

Great progress has been made in Computational Fluid Dynamics (CFD) in the past several decades, and nowadays it plays an important role in the design and analysis for aircraft development. The emerging problem for the commercial aircraft development is how to reduce the airframe noise from high lift device and landing gear. CFD has been widely used to predict the flow around the high lift device to reduce the aerodynamic noise, whereas the application of CFD to the landing gear is still limited [1-6]. The landing gear is constructed with many bluff components, and thus the noise source is not singular but many and thus complicated. To predict the noise from the real landing gear geometry precisely, all the components need to be modeled in the computation to treat all the interaction effect. Japan Aerospace Exploration Agency (JAXA) has developed a research landing gear model with detailed components based on the current two-wheel landing gear to understand the noise generation mechanism by experiments and numerical analysis. The model, Landing gear Evaluation Geometry model (LEG), includes all the components even with pins, tubes, and cavity as shown in Figure 1 [4-6]. To analyze the flow and acoustic field of the landing gear, the computational capability to these complicated geometries and the high parallelization performance are required.

To satisfy all these demands, Building-Cube Method (BCM) has been proposed, which is a block-structured Cartesian mesh solver [7-13]. In BCM, three-dimensional flow fields are divided into various sizes of cuboids called "Cube," and the cubes are subdivided into equally spaced Cartesian meshes called "Cell." As the mesh resolution is determined according to the local cube size, fine meshes near the body and coarse meshes far from the body can be accomplished. Because of the uniform computational load at each cube, it is expected to achieve the high parallel performance even with the massive number of processors. Since BCM is a Cartesianbased mesh, a complicated geometry such as a landing gear with tiny components can be easily and instantly meshed $[7,13]$. 


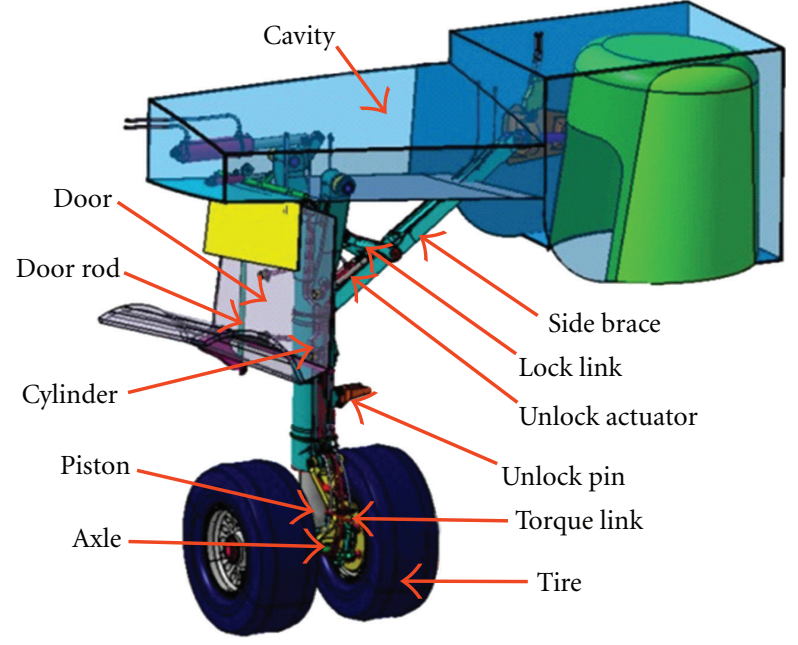

FIGURE 1: JAXA's two-wheel main landing gear model (LEG model) [4-6].

Compressible Navier-Stokes equation represents the propagation of sound wave, thus we can calculate aerodynamic sound directly in theory. However, because this propagation is a very tiny pressure fluctuation, it requires an enormous amount of mesh to calculate, and thus it is not a practical method. Therefore, we adopt aerodynamic/acoustic splitting method in this study. The pressure on a body surface is computed by an incompressible Navier-Stokes flow solver of BCM, and then the far-field sound level is estimated by means of Curle's equation [14]. In our previous result, the far-field noise from a landing gear was estimated but the large difference of SPL was observed [7]. In this paper, noncompact form of Curle's equation is adopted for farfield noise prediction to be able to handle acoustically noncompact objects. The method is validated using a circular cylinder case to estimate the far-field sound level. The present approach is then applied to JAXA's landing gear model, LEG geometry. The geometry is composed of many detail components: Main cylinder (strut), Center piston, Axle, Brake caliper, Brake disk, Wheel cap with cooling holes, and so forth. One of the objectives of this research is to evaluate the usefulness of non-compact form of Curle's equation against the landing gear noise by comparing with experimental data. Another is to investigate the influence of a torque link position and wheel cap shape to local flow features and also far-field aerodynamic noise. Through the computational analysis, the usefulness of the present method toward airframe noise estimation is discussed.

\section{Numerical Method}

2.1. Splitting Method. There are two major approaches for the aeroacoustic analysis: the direct method and the splitting method. In this paper, we adopt the latter, as it is popular particularly for low Mach number flows. The flowfield is analyzed by an unsteady flow simulation and the sound propagation is calculated by an acoustic analogy.
Three-dimensional incompressible flow solver is used as a flow solver and Curle's equation is adopted as aeroacoustic analogy. Firstly, the pressure fluctuation on the body surface is calculated by the BCM flow solver. Based on the timedependent surface pressure, far-field Sound Pressure Level (SPL) is obtained via the Curle's equation.

2.2. Flow Analysis. BCM is based on a multiblock structure of equally spaced Cartesian meshes to achieve the simplicity in the mesh generation, in the spatially higher-order solution algorithm, and in the postprocessing. These features of simplicity of the Cartesian mesh apply to all stages of a flow computation and eases memory requirement per node. These factors will become more important for large-scale computations on expected near-future high performance computers. The computational mesh consists of many cuboids which include equally spaced Cartesian mesh as shown in Figure 2. It shows cube and cell distribution around NACA0012 airfoil. These cuboids in Figure 2(a) are called as "cube," and Cartesian mesh in each cube are called as "cell" in Figure 2(b). Since the number of mesh points is completely the same in all the cubes regardless the cube size, high parallel efficiency is accomplished as the computation is parallelized based on cube. The mesh resolution is controlled by each cube size, thus the geometrical size of cube becomes large as the increase of distance from a wall boundary. In the present approach, the body surface is approximated as staircase representation for the simplicity. To improve the local mesh resolution, selected cubes can be subdivided.

Governing equations of the present solver are incompressible Navier-Stokes equations as follows:

$$
\begin{aligned}
\frac{\partial \mathbf{u}}{\partial t}+(\mathbf{u} \cdot \nabla) \mathbf{u} & =-\nabla p+\frac{1}{\operatorname{Re}} \nabla^{2} \mathbf{u}, \\
\operatorname{div} \mathbf{u} & =0 .
\end{aligned}
$$

The staggered arrangement is employed with finite difference scheme in terms of the spatial accuracy. In this study, the convective term is discretized by Kawamura-Kuwahara scheme based on a third-order upwind scheme [15]. The pressure term is solved by Red-Black SOR method, and the diffusion term is discretized by a second-order central difference scheme. The time integration uses Fractional-Step method, and the temporal velocity field is solved by secondorder Adams-Bashforth explicit method [12]. Simple linear interpolation is employed for the data interchange for the compromise between computational efficiency and accuracy. Higher-order interpolation maintains the computational accuracy and the mass conservation; however, it deteriorates the computational efficiency and increases memory usage. Thus, the smallest cubes are allocated around the body and also the wake region in the present computation to minimize the influence of linear interpolation between different size cubes.

2.3. Acoustic Analysis. The general theory about the aeroacoustic generation was developed by Lighthill in 1952 [16]. Lighthill transformed the Navier-Stokes and continuity equations to form an exact, inhomogeneous wave equation, 


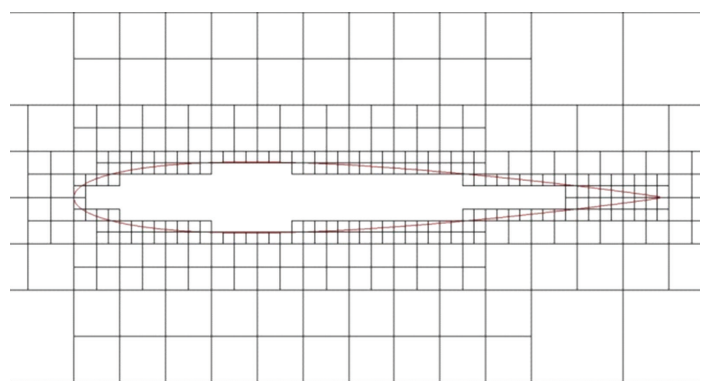

(a) Cube allocation

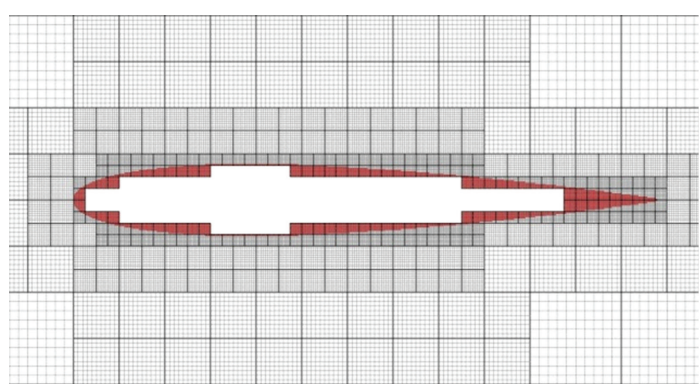

(b) Cell distribution

FIgURE 2: Cube and cell distribution around an airfoil with BCM.

where the source terms were considered only within turbulent flow region. The Lighthill equation, which represents the sound propagation in the static fluid, is described as follows:

$$
\frac{\partial^{2} \rho^{\prime}}{\partial t^{2}}-c_{0}^{2} \nabla^{2} \rho^{\prime}=\frac{\partial^{2} T_{i j}}{\partial x_{i} \partial x_{j}}
$$

The equation means that the aeroacoustic noise is generated by quadrupole source in the static fluid. The Lighthill equation does not consider the existence of an object in the flow. Curle revealed that sound source was generated by quadrupole source at the turbulent flow and dipole source at the surface of an object, and led to the following equation:

$$
\rho^{\prime}=\frac{1}{4 \pi c_{0}^{2}} \frac{\partial^{2}}{\partial x_{i} \partial x_{j}} \int_{V} \frac{\left\lfloor T_{i j}\right\rfloor}{r} d V-\frac{1}{4 \pi c_{0}^{2}} \frac{\partial}{\partial x_{i}} \int_{S} \frac{\left[P_{i}\right]}{r} d S .
$$

Curle's equation was obtained by the transformation of the Lighthill equation to form an exact integral equation. However, the equation is not easy to solve since it requires the computation of volume integration and space derivative. Curle's equation can be simplified with the assumption of low speed flow. The first term of (3) can be ignored because the magnitude of the term is square of the Mach number. The space derivative is then converted into temporal differentiation, and the equation is represented as follows:

$$
P_{a}=\frac{1}{4 \pi c_{0}} \frac{x_{i}}{r^{2}} \frac{\partial}{\partial t} \int P_{i}\left(y, t-\frac{r}{c_{0}}\right) d S
$$

This compact form of Curle's equation means that the sound pressure at the observation point from the object is computed via the surface pressure fluctuation. This equation is valid when the acoustically compact condition is satisfied. The compact condition is that the sound wavelength is much longer compared to the characteristic length of an object, and also the sound observation point is far away enough from the object compared to the sound wavelength. In this study, the following noncompact form of Curle's equation is introduced to treat the acoustic field where the acoustically compact is not satisfied

$$
P_{a}=\frac{1}{4 \pi} \int \frac{x_{i}-y_{i}}{r^{2}}\left(\frac{1}{c_{0}}\left[\frac{\partial P_{i}}{\partial t}\right]+\frac{\left[P_{i}\right]}{r}\right) d S .
$$

The sound source position is not singular in the equation unlike (4). The equation is named non-compact Curle's equation in this study, whereas (5) is named compact Curle's equation for the distinction. To measure the SPL at the observation point, the pressure fluctuation calculated by the Curle's equation is transformed into the fluctuation in the frequency domain by FFT (Fast Fourier Transform). Then, it is substituted into the following equation:

$$
\mathrm{SPL}=10 \log _{10}\left(\frac{P_{e}^{2}}{P_{0}^{2}}\right) .
$$

Here, $P_{e}$ is the effective value of the sound pressure fluctuation calculated by the FFT, and $P_{0}$ is the reference sound pressure in air, whose value is $2.0 \times 10^{-5}[\mathrm{~Pa}]$.

\section{Circular Cylinder}

3.1. Computational Condition. A circular cylinder is used for the validation of aeroacoustic noise prediction using the present aerodynamic/acoustic splitting method of BCM and Curle's method. The BCM meshes based on the cylinder diameter $D(0.04 \mathrm{~m})$ is generated in the computational domain shown in Figure 3. The computational domain size is $50 D \times 50 D$, and the cylinder height is $12.5 D(0.5 \mathrm{~m})$. The minimum mesh spacing is $1.0 \times 10^{-2} \mathrm{D}$, and the total number of cells amounts to 100 million. Cube allocation from the side view is shown in Figure 3(b), where finer cube is used behind the cylinder to distribute high-resolution mesh in the wake region. Reynolds number is $2.0 \times 10^{4}$ based on the cylinder diameter, uniform flow velocity is $7.5 \mathrm{~m} / \mathrm{s}$, and the observation point is $25 \mathrm{D}(1.0 \mathrm{~m})$ aside from the cylinder. Sommerfeld boundary condition is used at the downstream boundary condition to prevent the unphysical reflection of pressure wave at the boundary. In the FFT calculation, the sampling frequency is $1,280 \mathrm{~Hz}$ (6.3 in nondimensional frequency), the frequency resolution is $2.5 \mathrm{~Hz}(0.133$ in non-dimensional frequency). FFT length is 512, FFT average is 10 times, and the overlap is $50 \%$. The parameters used in the computation are summarized in Table 1 .

3.2. Result. The computational result of SPL is compared with experimental data [17] as shown in Figure 4. Both the results of compact Curle's equation (2) and non-compact 


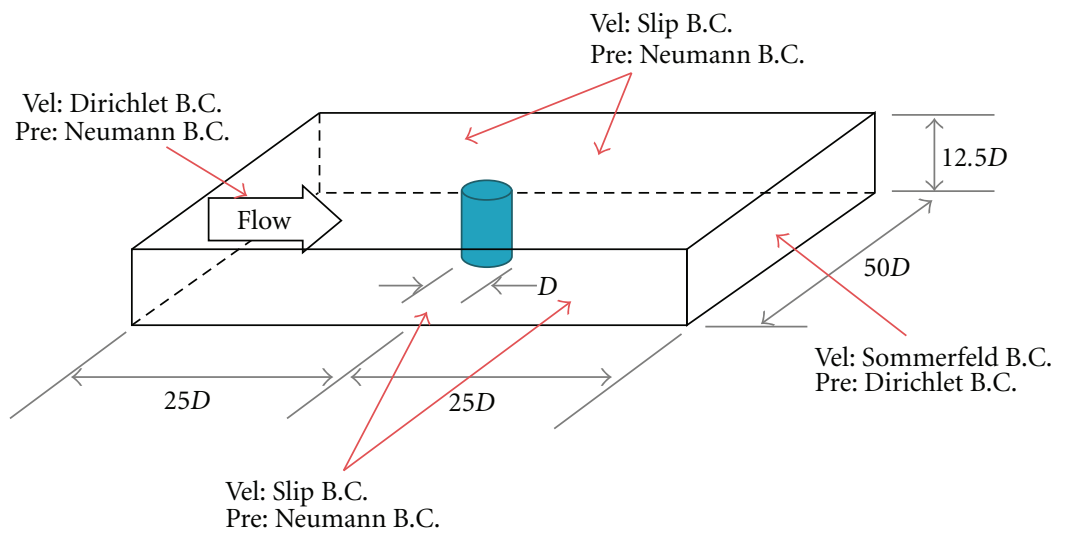

(a) Computational domain

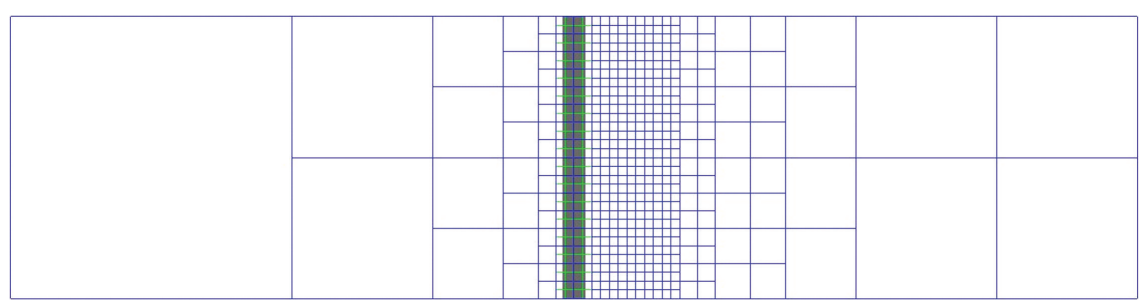

(b) Cube allocation (viewed from the side)

FIgURe 3: Computational domain with boundary conditions and Cube allocation.

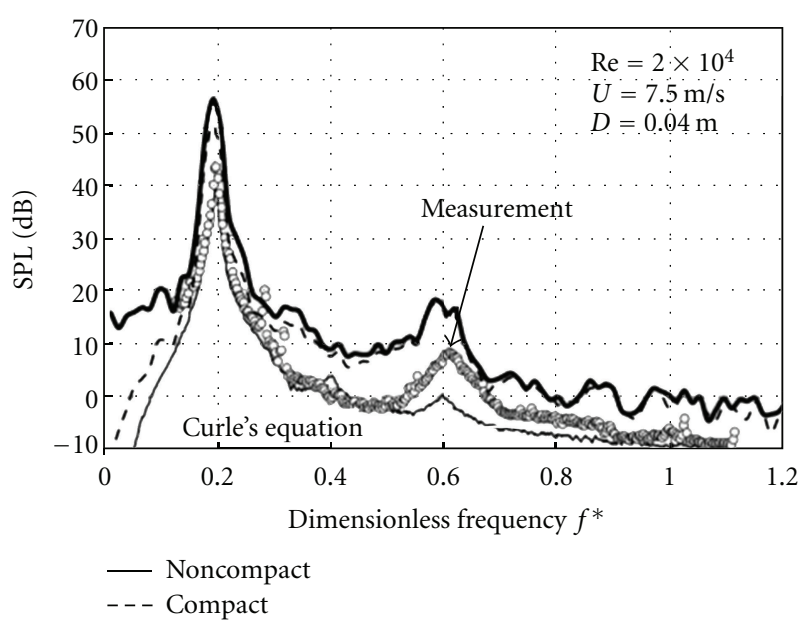

FIGURE 4: SPL spectrum of computational end experimental results.

Curle's equation (3) are plotted for comparison. The bold line is calculated by the non-compact Curle's equation, the dot-line is calculated by compact Curle's equation, the circle is the experimental result, and the slim line is calculated by the authors of [17] using compact Curle's equation. The spectrum of the non-compact Curle's equation is generally matched with those of compact Curle's equation and experiment. However, the SPL of first peak is much higher compared to the experiment. This is because non-compact Curle's equation considers the near-field pressure fluctuation (pseudo acoustic wave). Meanwhile, the effect of pseudo acoustic wave is removed for the experimental result. The raw
TABLE 1: Computational condition of a circular cylinder.

\begin{tabular}{ll}
\hline Reynolds number, Re & $2.0 \times 10^{4}$ \\
Characteristic length, $D$ & $0.04[\mathrm{~m}]$ (cylinder diameter) \\
Freestream velocity & $7.5[\mathrm{~m} / \mathrm{s}]$ \\
Computational domain & $50 D \times 50 D \times 12.5 D$ \\
Minimum mesh spacing & $1.00 \times 10^{-2} \mathrm{D}$ \\
Total number of cells & about 100 million \\
Sampling frequency & $6.3[-](1280 \mathrm{~Hz})$ \\
Frequency resolution & $0.133[-](2.5 \mathrm{~Hz})$ \\
Length of FFT & 512 \\
Averaging & 10 times \\
Overlap & $50 \%$ \\
\hline
\end{tabular}

SPL at the first peak of experiment is $51.7 \mathrm{~dB}$, and then the difference with non-compact result becomes $4 \mathrm{~dB}(55.0 \mathrm{~dB}$ by non-compact SPL at the first peak). The usefulness of the present splitting method is validated, though the difference between compact and non-compact Curle's equation is small for the case of cylinder.

\section{LEG Model}

4.1. Computational Condition. The simplified LEG model is used for the simulation to understand the influence of axle region to flows and far field noise. As shown in Figure 5, the simplified LEG geometry is composed of a main cylinder (strut), a center piston, a torque link, axle and brake components, and two wheels. The simplified LEG model 


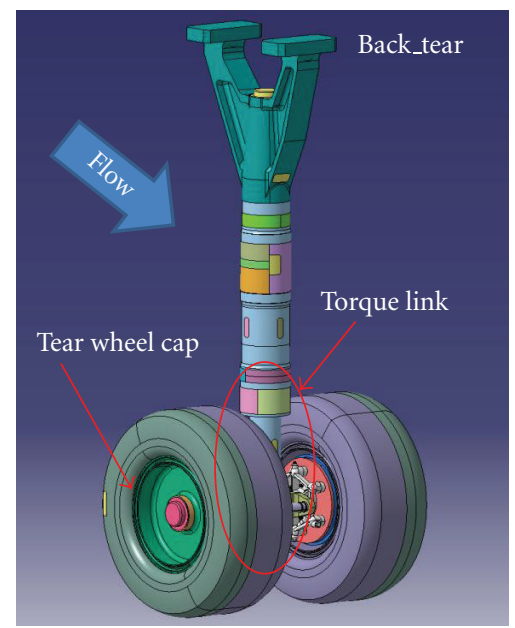

(a) BACK_TEAR configuration

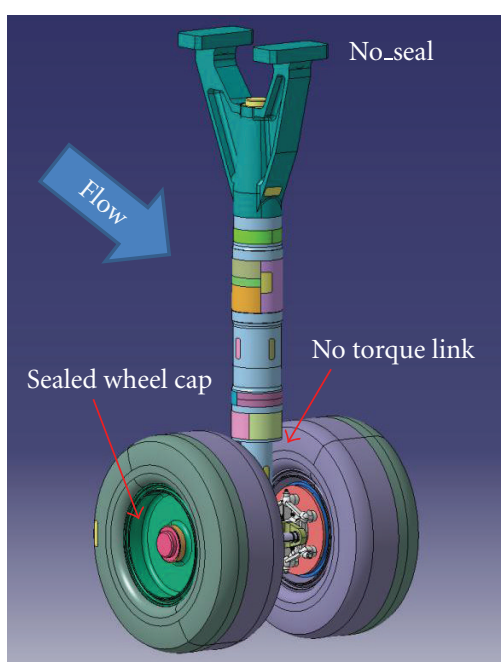

(b) NO_SEAL configuration

FIGURE 5: Simplified LEG geometries for computation.

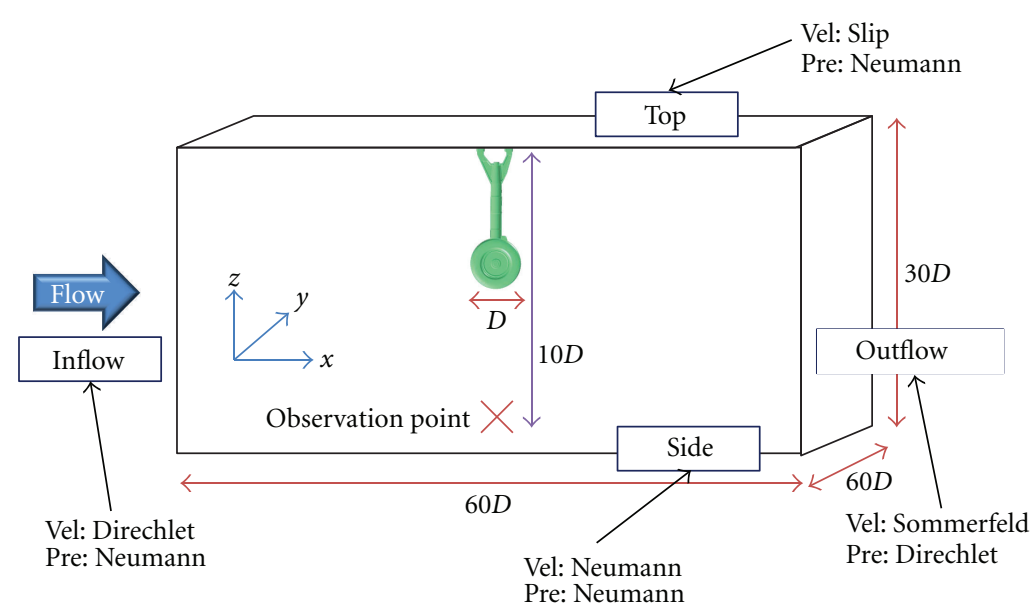

(a) Computational domain with boundary conditions

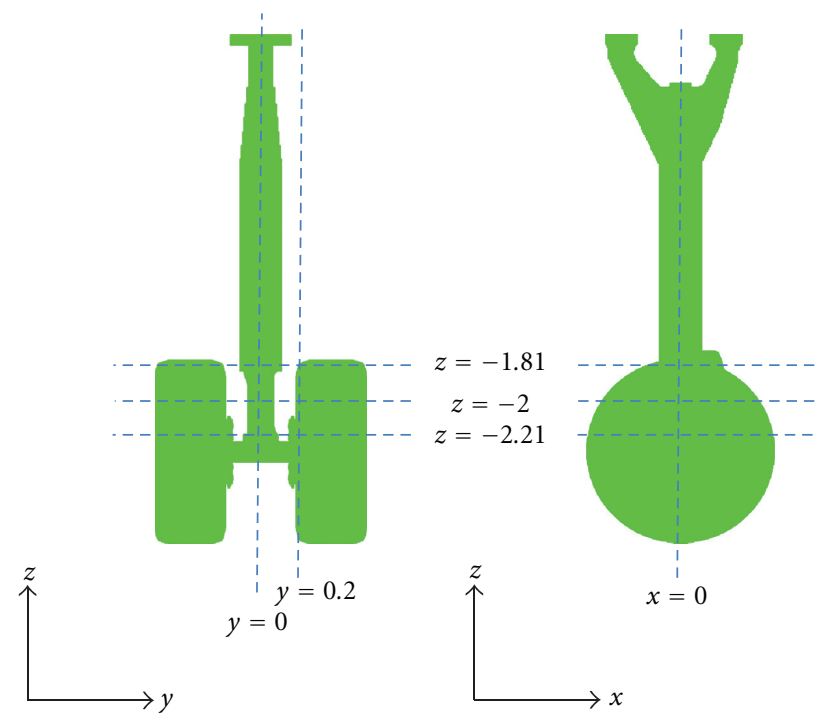

(b) Model with cross sections

FIGURE 6: Computational domain and model cross sections. 


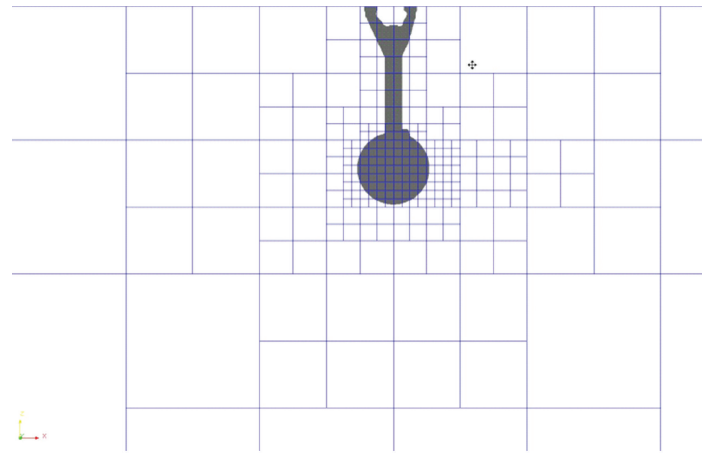

(a) Cube allocation

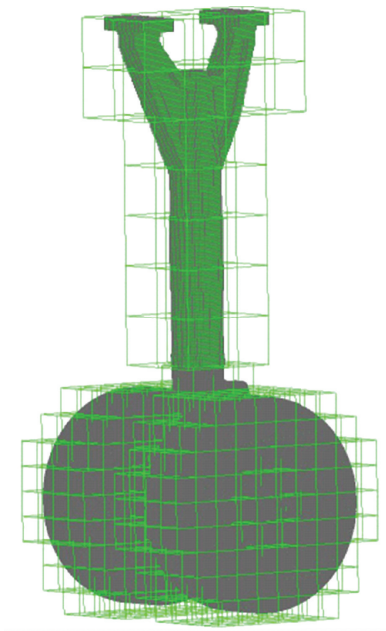

(b) Wall cube allocation

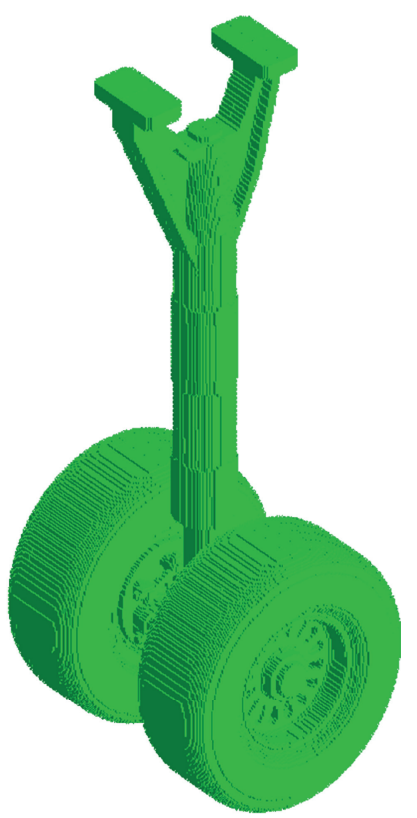

(c) Surface cells (staircase representation)

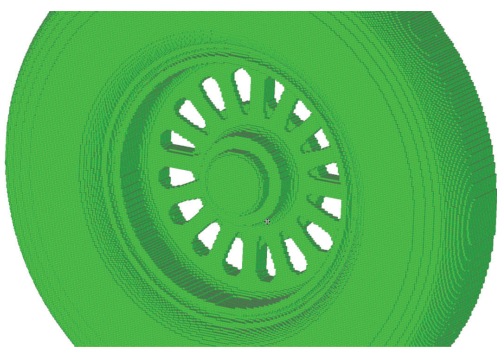

(d) Cells at wheel

FIgURE 7: Computational mesh for LEG geometry.

does not have other major components such as a door, a side-brace, and cavity shown in Figure 1. The torque link position is variable, so that the torque link can be attached in front of the strut, behind the strut (Figure 5(a)), or even removed (Figure 5(b)) to evaluate the influence of torque link to the flowfield and aerodynamic noise. In addition, there are two types of wheel cap prepared: the sealed cap (Figure 5(b)) and the tear-shaped cooling holes on the cap (Figure 5(a)). The cooling holes are penetrating the wheel cap, thus the tiny flow paths exist in the wheel. Computations are conducted for the six configurations by changing the position of the torque link and by changing the wheel cap geometry as summarized in Table 2. Each name in the table means [Torque link position]_[Wheel cap type]. BACK_TEAR geometry is that the torque link is attached backward the strut (BACK) and the wheel cap is tear-shaped cooling holes type (TEAR) as shown in Figure 5(a).

The BCM meshes based on the wheel diameter $D(0.4 \mathrm{~m})$ are generated for the six LEG geometries. The computational domain size is $60 D \times 60 D \times 30 D$, and the LEG geometry is attached to slip wall as shown in Figure 6(a). Figure 6(b) shows the model with several cross-sections where the
TABle 2: Six LEG configurations.

\begin{tabular}{lcc}
\hline Name & Torque link position & Wheel cap type \\
\hline BACK_SEAL & BACK & SEALED \\
BACK_TEAR & BACK & TEAR (Cooling Hole) \\
FRONT_SEAL & FRONT & SEALED \\
FRONT_TEAR & FRONT & TEAR (Cooling Hole) \\
NO_SEAL & NO (REMOVED) & SEAL \\
NO_TEAR & NO (REMOVED) & TEAR (Cooling Hole) \\
\hline
\end{tabular}

computed flowfields are compared. Cube allocation from the side view is shown in Figure 7(a). Subdivided cubes are allocated at the wake region to improve the mesh resolution. Wall cubes around the wheel region are also refined as shown in Figure 7(b). The whole surface cells with staircase representation is shown in Figure 7(c). Cooling holes at the wheel are sufficiently represented with the minimum mesh spacing of $3.66 \times 10^{-3} \mathrm{D}$ (based on the wheel diameter) as shown in Figure 7(d). The total number of cells amounts about 90 million, and the flow computations are conducted on the vector-parallel supercomputer of NEC SX-9 16 CPUs. 




(a) Cross section at $y=0.0$

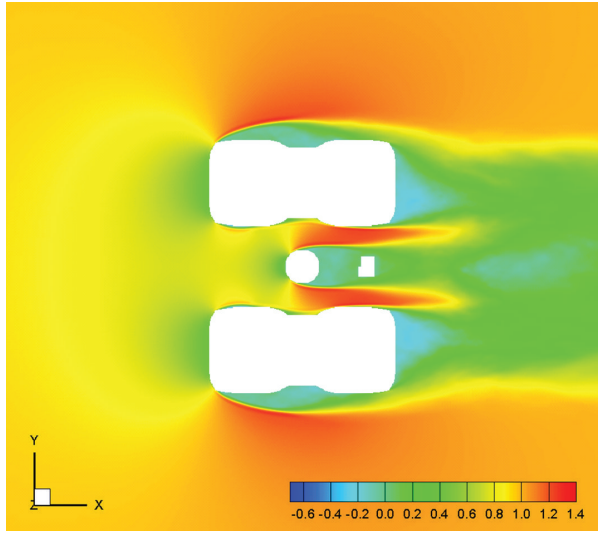

(b) Cross section at $z=-2.00$

FIgURE 8: Computed mean velocity component in the freestream direction.
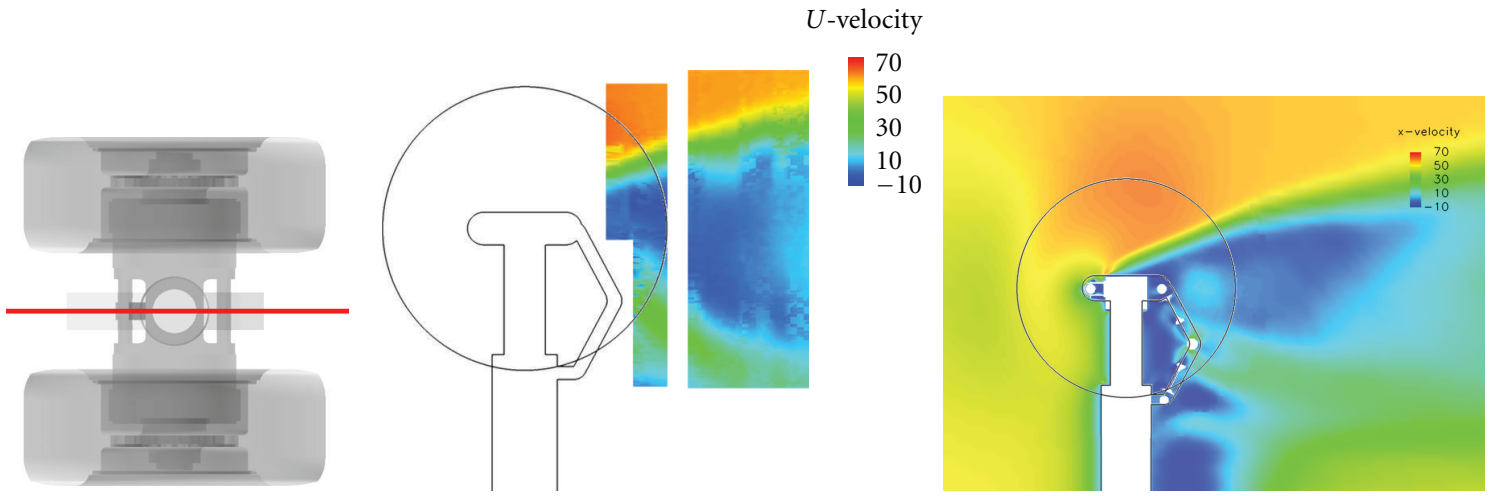

(a) PIV measurement (left) and computation (right) at cross section $y$
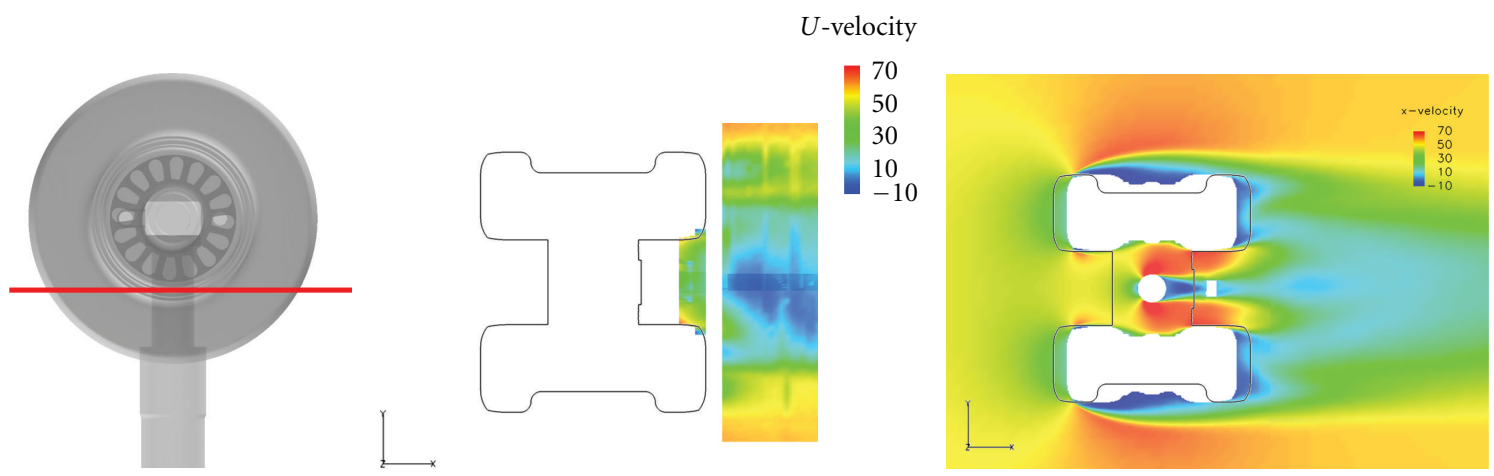

(b) PIV measurement (left) and computation (right) at cross section $z$

Figure 9: Mean velocity component in the freestream direction by Murayama et al. [6].

Reynolds number is 1.49 million based on the wheel diameter $D$, uniform flow velocity is $54.4 \mathrm{~m} / \mathrm{s}$, and the observation point is $14.71 \mathrm{D}$ below the model. In the FFT calculation, the sampling frequency is $10 \mathrm{kHz}$ (75 in non-dimensional frequency), the frequency resolution is $20 \mathrm{~Hz}$ (0.147 in non-dimensional frequency). The other setting is same as the cylinder case: FFT length 512, FFT average 10 times, and the overlap 50\%. Table 3 summarizes the computational condition.
4.2. LEG with Backward Torque Link Configuration. The LEG configuration with backward torque link and wheel cap of cooling holes (BACK_TEAR) is used for comparison. The mean velocity component in the freestream direction at the two sections ( $y=0.0$ and $z=-2.00$ ) is shown in Figure 8. Figure 8(a) shows the flowfield at the center of the landing gear, and the separation from the axle is observed. The geometry is upside down, but the result is in reasonable agreement with Murayama's PIV measurement data and 


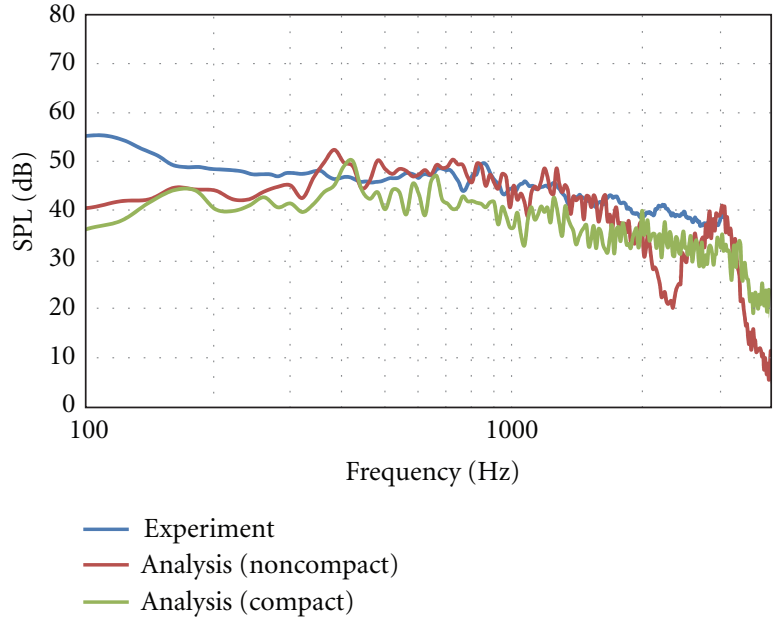

(a) Narrow band

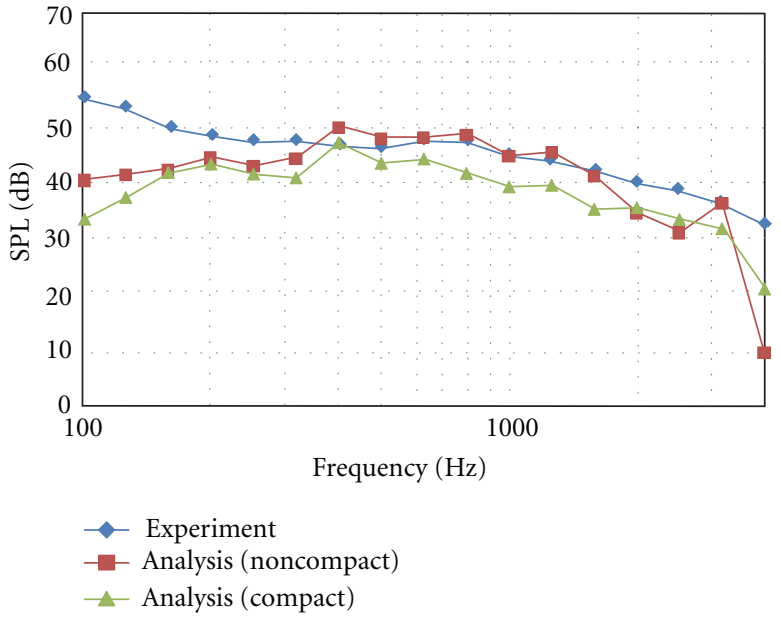

(b) 1/3-octave band (experimental scale)

FIgURE 10: Comparison of SPL spectrum by experiment and computations.

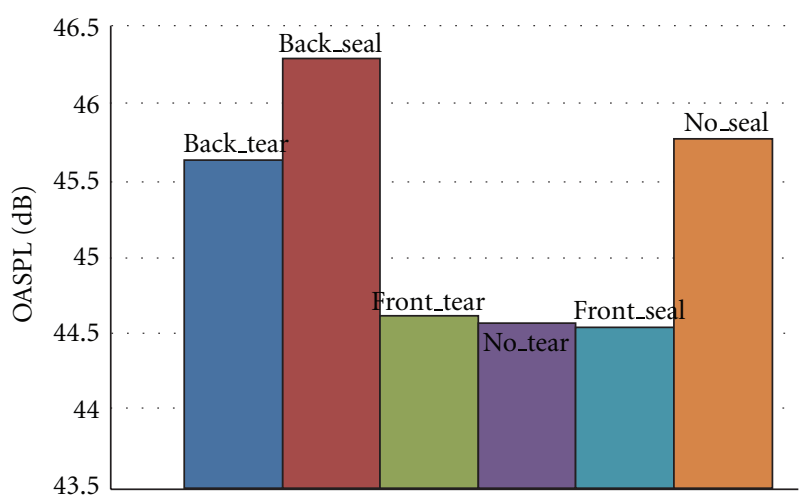

(a) Computational result



(b) Experimental result

FIgURE 11: Comparison of OASPL of different LEG configurations.

TABLE 3: Computational condition of LEG model.

\begin{tabular}{ll}
\hline Reynolds number, Re & $1.49 \times 10^{6}$ \\
Characteristic length, $D$ & $0.4[\mathrm{~m}]($ wheel diameter $)$ \\
Freestream velocity & $54.4[\mathrm{~m} / \mathrm{s}]$ \\
Computational domain & $60 D \times 60 D \times 30 D$ \\
Minimum mesh spacing & $3.66 \times 10^{-3} \mathrm{D}$ \\
Total number of cells & About 90 million \\
Sampling frequency & $75[-](10[\mathrm{kHz}))$ \\
Frequency resolution & $0.147[-](20[\mathrm{~Hz}])$ \\
Length of FFT & 512 \\
Averaging & 10 times \\
Overlap & $50 \%$ \\
\hline
\end{tabular}

computational result [6] in Figure 9(a). Figure 8(b) shows the velocity field near the axle region. The flow acceleration due to the existence of the center cylinder and the torque link is observed. The flowfield are similar to the PIV data and computation; however the acceleration region is larger compared to the referenced computation.
The SPL spectrum in narrow band and also the converted spectrum to $1 / 3$ octave band (experimental scale) are plotted in Figure 10. The figures include numerical results based on compact and non-compact forms of Curle's equations, and also experimental result. The SPL based on compact Curle's equation shows a $10 \mathrm{~dB}$ difference compared to experiments as compared to the previous result in [7]. By applying noncompact Curle's equation, the SPL values between 200 and $3,000[\mathrm{~Hz}]$ frequency range are much improved, and the values are closely agreed with experimental data. The sharp decrease of SPL is shown in the present computation at the higher frequency range. The problem needs to be solved for more accurate prediction in the entire frequency domain but this can be caused due to the lack of mesh resolution. Since the background noise is not considered in the computations, the SPL of the lower frequency range is smaller compared to the experiment.

4.3. OASPL for Six LEG Configurations. To compare the noise level of the six LEG configurations, the Overall SPL (OASPL) 




(a) BACK_SEAL configuration



(c) FRONT_TEAR configuration

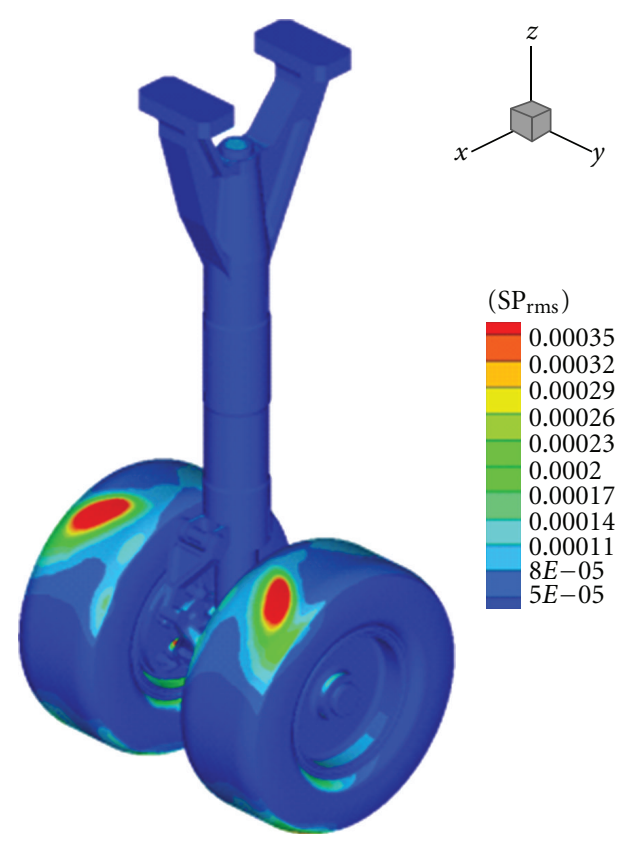

(b) BACK_TEAR configuration

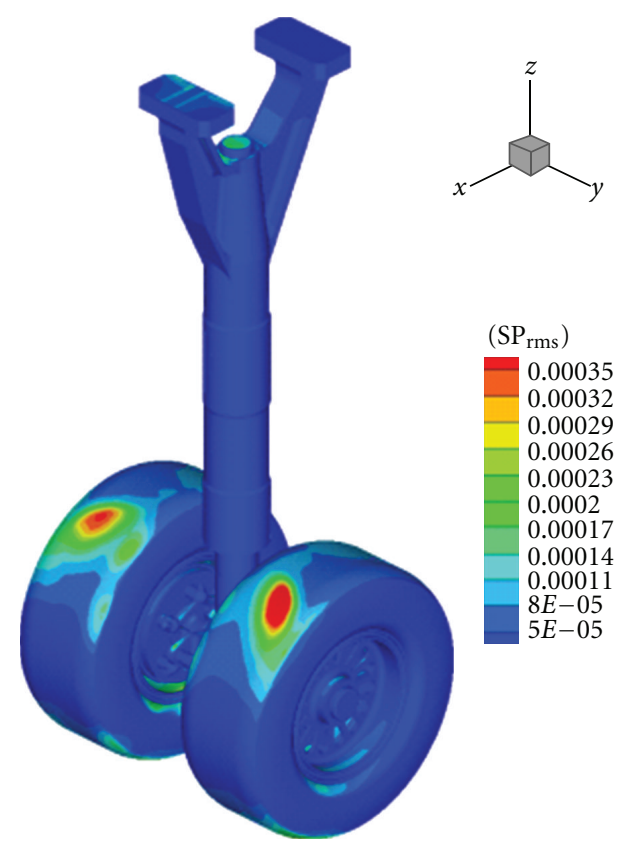

(d) NO_TEAR configuration

FIGURE 12: Comparison of surface sound pressure fluctuation of different LEG configurations (viewed from behind the landing gear).

is computed in this section. The OASPL is computed by integrating the power of spectrums as follows:

$$
\text { OASPL }=10 \log _{10}\left(\frac{\sum_{f_{1}}^{f_{2}} p^{2}}{P_{0}{ }^{2}} \frac{\Delta f}{f_{2}-f_{1}}\right) .
$$

In this study, the integral range of frequency is from 220 to $3,500[\mathrm{~Hz}]$ because the range shows reasonable agreement with the experiment in the previous section.
The computational and experimental OASPL values of the LEG configurations are shown in Figure 11. Four out of six configurations were examined by the experiment, while all the six configurations were evaluated by the present computations. In the experimental result, the torque link position highly affects the OASPL. When the location is behind the piston, higher OASPL values are observed. The noisiest configuration is BACK_SEAL in the experiment. The computational result shows that the tendency of OASPL is in qualitative agreement with the experiment; the BACK_SEAL 




(a) BACK_TEAR configuration



E-05

E-05

FIGURE 13: Comparison of surface sound pressure fluctuation below the wheel.
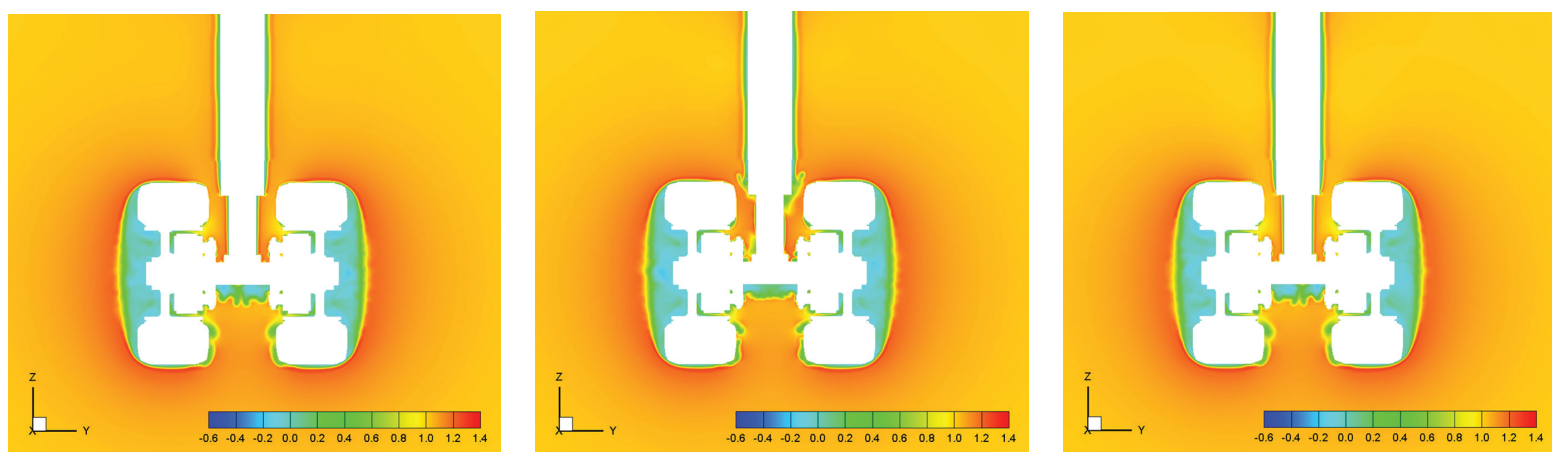

(a) Velocity component in the freestream direction
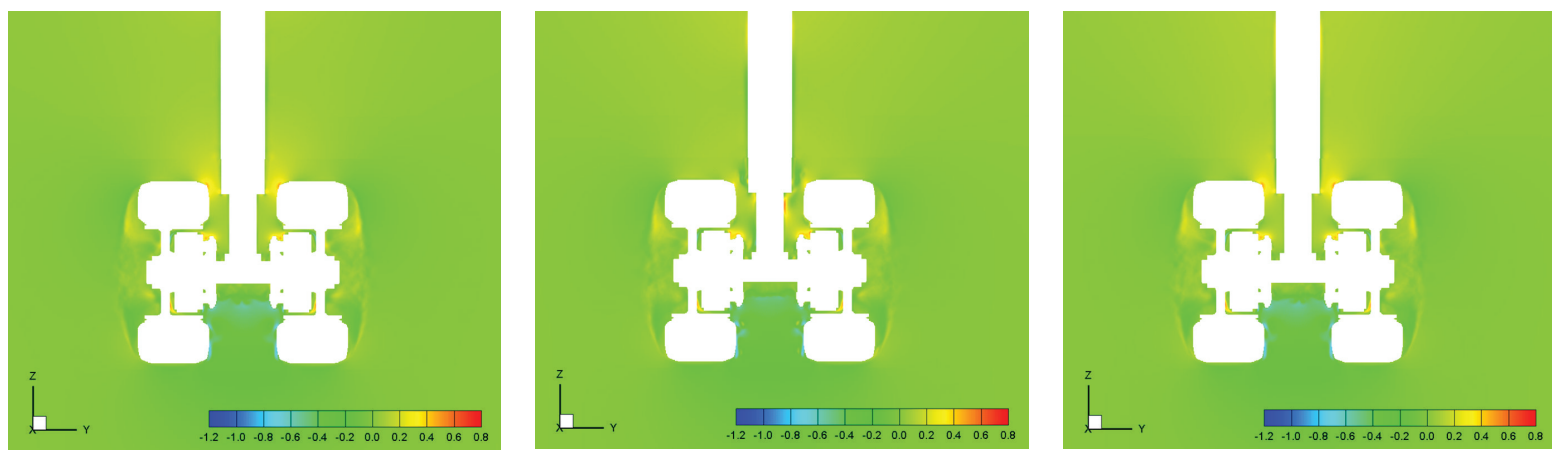

(b) Velocity component in the vertical direction

FIGURE 14: Computed mean velocity component at cross section $x=0.0$ (left: BACK_TEAR, center: FRONT_TEAR, right: NO_TEAR).

is noisiest, and the second is BACK_TEAR of the four. From the computational results, OASPL values tend to be high when the torque link position is behind the piston or removed from the geometry together with the sealed wheel cap. On the other hand, when the torque link is attached in front of the piston against the flow, the values are almost the same regardless the wheel cap type: sealed or tear holes. This indicates that the torque link position highly affects the far-field aerodynamic noise from landing gear as its existence drastically changes the flow characteristics.
Sound pressure fluctuation on the surface $\left(\mathrm{SP}_{\mathrm{rms}}\right)$ is calculated by non-compact form of Curle's equation. Since the Curle's equation converts surface pressure fluctuations to the noise at the observation point, the surface with larger $\mathrm{SP}_{\mathrm{rms}}$ has larger contribution to the noise. The surface sound pressure fluctuations of the four configurations (BACK_SEAL, BACK_TEAR, FRONT_TEAR, NO_TEAR) are plotted in Figure 12. It is observed that one part of the upper wheel (toward the root of landing gear) shows the higher values. The appearance of BACK_SEAL, BACK_TEAR, 

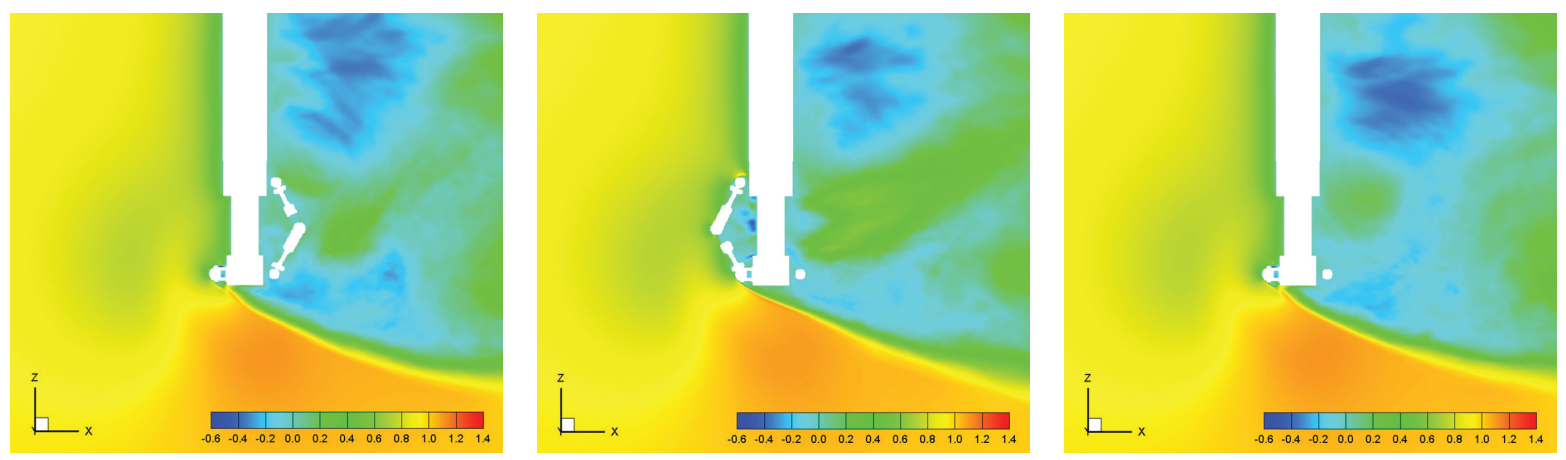

(a) Velocity component in the freestream direction
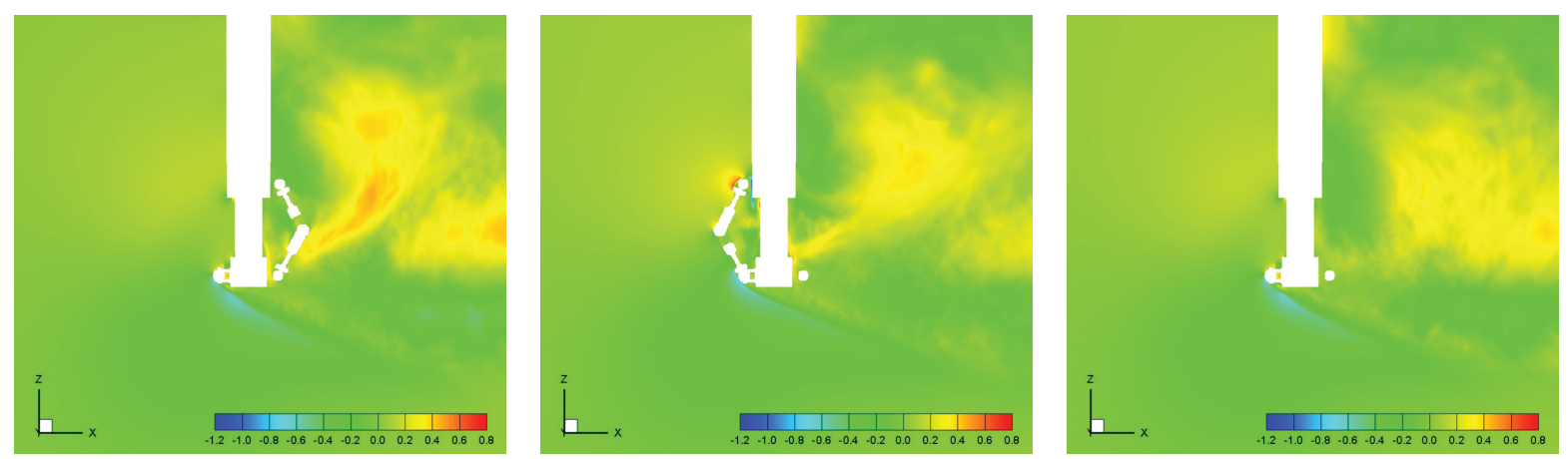

(b) Velocity component in the vertical direction

FiguRE 15: Computed mean velocity component at cross section $y=0.0$ (left: BACK_TEAR, center: FRONT_TEAR, right: NO_TEAR).


(a) Velocity component in the freestream direction
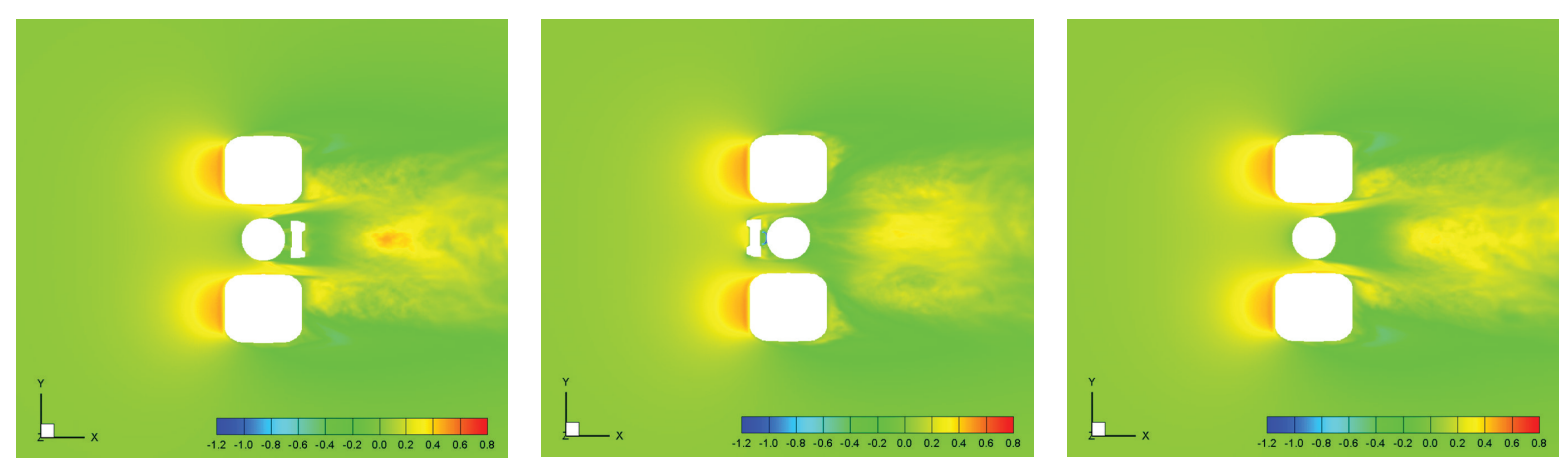

(b) Velocity component in the vertical direction

FigurE 16: Computed mean velocity component at cross section $z=-1.81$ (left: BACK_TEAR, center: FRONT_TEAR, right: NO_TEAR). 

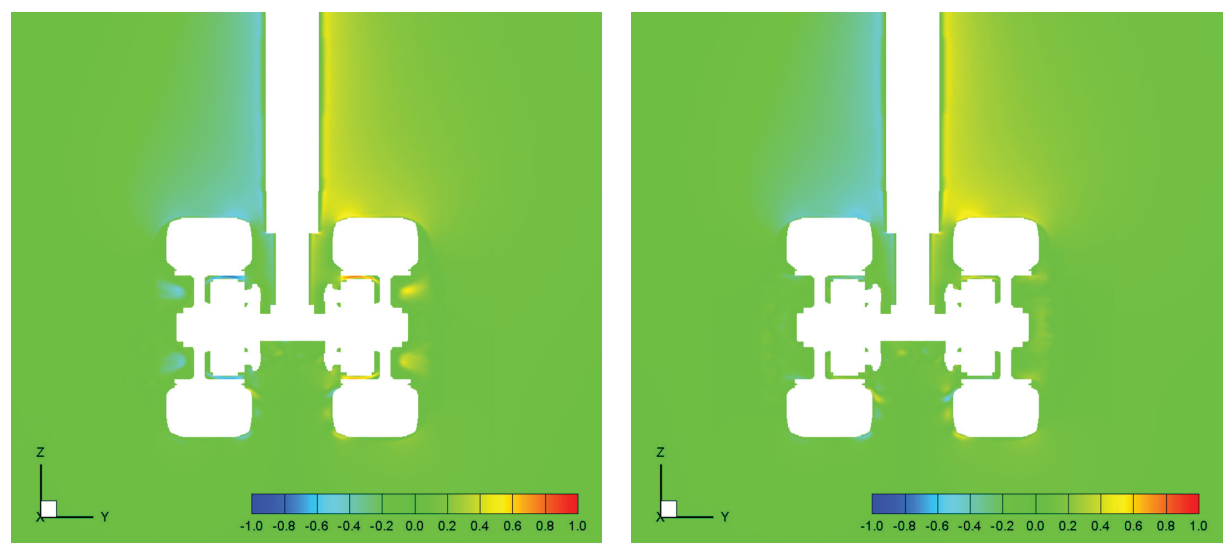

FIGURE 17: Computed mean velocity component in the horizontal direction at cross section $x=0.0$ (left: BACK_TEAR, right: BACK_SEAL).
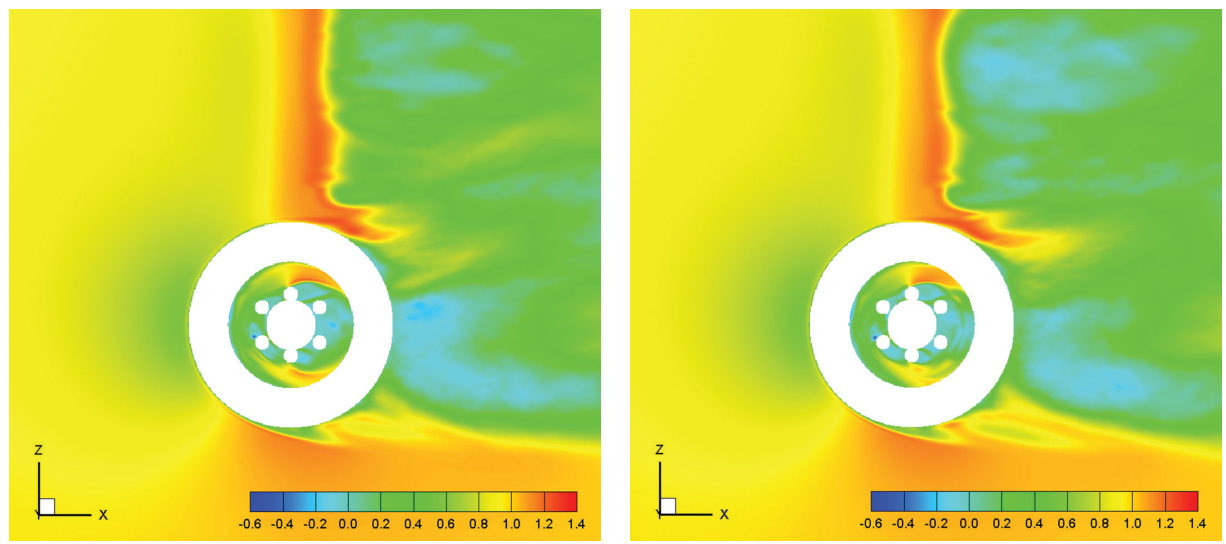

(a) Velocity component in the freestream direction
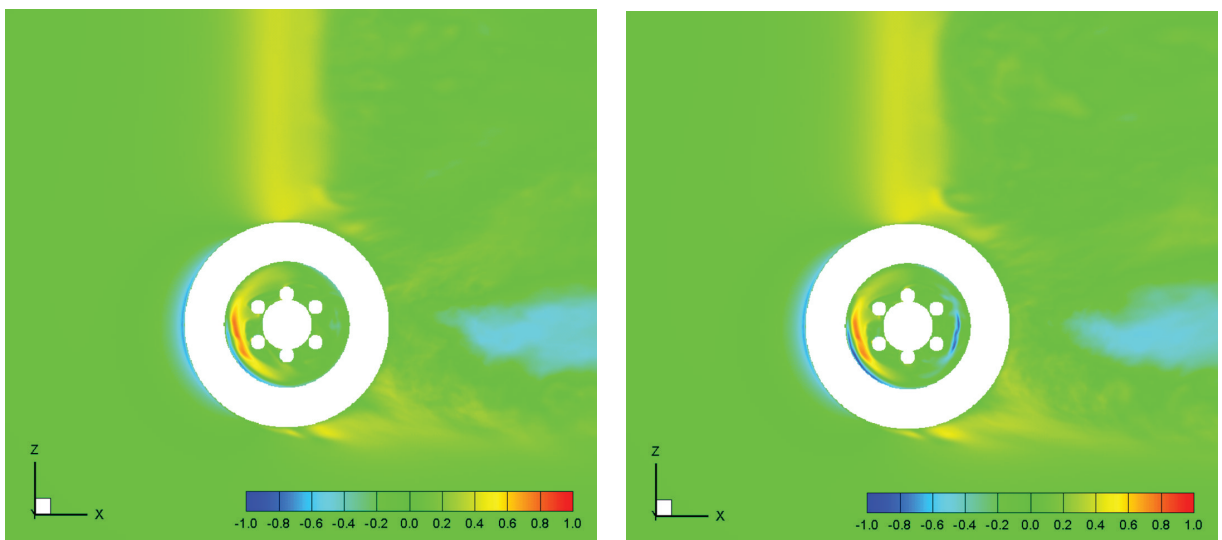

(b) Velocity component in the vertical direction

FIGURE 18: Computed mean velocity component in the horizontal direction at cross section $y=0.2$ (left: BACK_TEAR, right: BACK_SEAL).

and NO_TEAR are almost identical, whereas the values of NO_TEAR are slightly lower. Large difference is observed for FRONT_TEAR geometry as the higher value's region is shifted and the values get weaker. The difference is caused by the torque link position to be attached at the front.

4.4. Influence of Torque Link Position. As discussed in the previous section, forward torque link position affects the flow-field and reduces the noise compared to the backward torque link position. Surface sound pressure fluctuations at the axle for BACK_TEAR and FRONT_TEAR are shown in Figure 13. The difference is observed below the axle (toward observation point) and also the junction between the main cylinder and the piston. In addition to these areas, difference of upper wheel region as shown in Figure 12 causes the OASPL difference of the two geometries. 

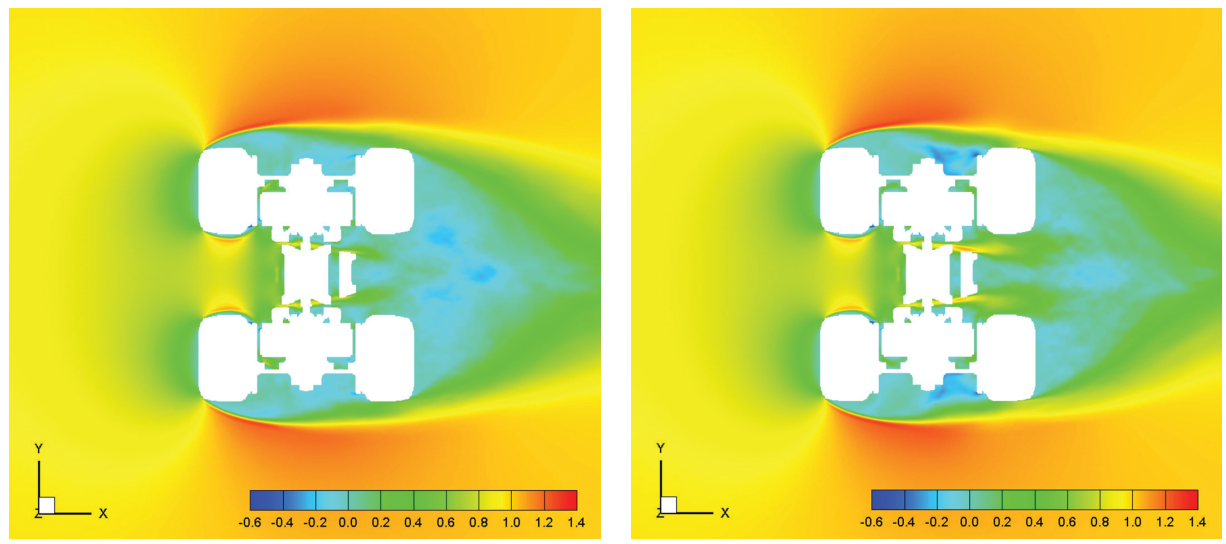

(a) Velocity component in the freestream direction
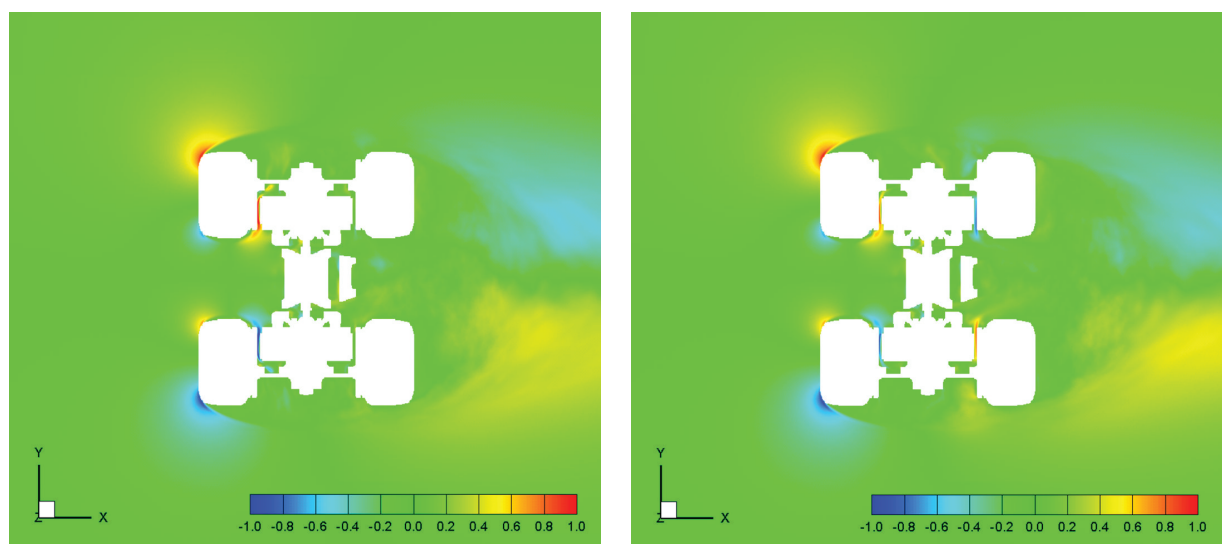

(b) Velocity component in the horizontal direction

FIGURE 19: Computed mean velocity component at cross section $z=-2.21$ ( left: BACK_TEAR, right: BACK_SEAL).

Three LEG configurations with forward/backward and without torque link are used to investigate the effect of torque link position: BACK_TEAR, FRONT_TEAR, NO_TEAR. Figures 14-16 show the mean velocity component of the three configurations at different cross-sections. Timeaveraged velocity component at $x=0.0$ section shows the large velocity difference at the main cylinder and the piston for BACK_TEAR and FRONT_TEAR as shown in Figure 14. The flow at the wheel corner (edge) is accelerated toward the landing gear root in BACK_TEAR, while the acceleration is weaker in FRONT_TEAR. This causes the difference of sound pressure fluctuations in Figure 12, and also the OASPL in Figure 11. Figure 15 shows the difference of the three geometries at $y=0.0$ due to the existence of the torque link. The change is appeared in front of the strut (separation) and behind the strut (wake region). In BACK_TEAR configuration, the backward torque link causes the flow circulation and the flow turning toward the root of landing gear in the wake. Figure 16 shows that the velocity between the wheel and the piston is accelerated in BACK_TEAR and NO_TEAR configurations. On the other hand, the acceleration in FRONT_TEAR is weaker because the existence of forwardattached torque link prevents the flow toward the freestream direction and also vertical direction (along with the cylinder).
When the torque link is attached forward (against the flow), the flow through the two wheels at axle region is not much accelerated. When the torque link is attached behind the cylinder or the torque link is removed, the flow between the two wheels is greatly accelerated, and this causes the large surface pressure fluctuations and also the noise increase at the observation point.

4.5. Influence of Wheel Cap Geometry. The influence of wheel cap geometry is discussed in this section. The LEG geometry with the sealed wheel (BACK_SEAL) and the LEG geometry with the tear-shaped cooling holes (BACK_TEAR) are used for comparison. Figure 17 shows the mean velocity component in horizontal direction at $x=0.0$. In BACK_TEAR configuration, the flow is induced from inside the wheel to outside the wheel through cooling holes, whereas no flow goes through the sealed wheel cap in BACK_SEAL configuration. Figures 18 and 19 show the mean velocity components of the two geometries at different cross sections. The difference of the flowfield is relatively small. It is observed that the flow at the front part of axle region goes into the wheel disk space for both configurations as shown in Figures 18(b) and 19(b). The difference is shown at the rear part of axle. The flow from the inside of wheel is induced to the outside of the wheel through the cooling holes in 

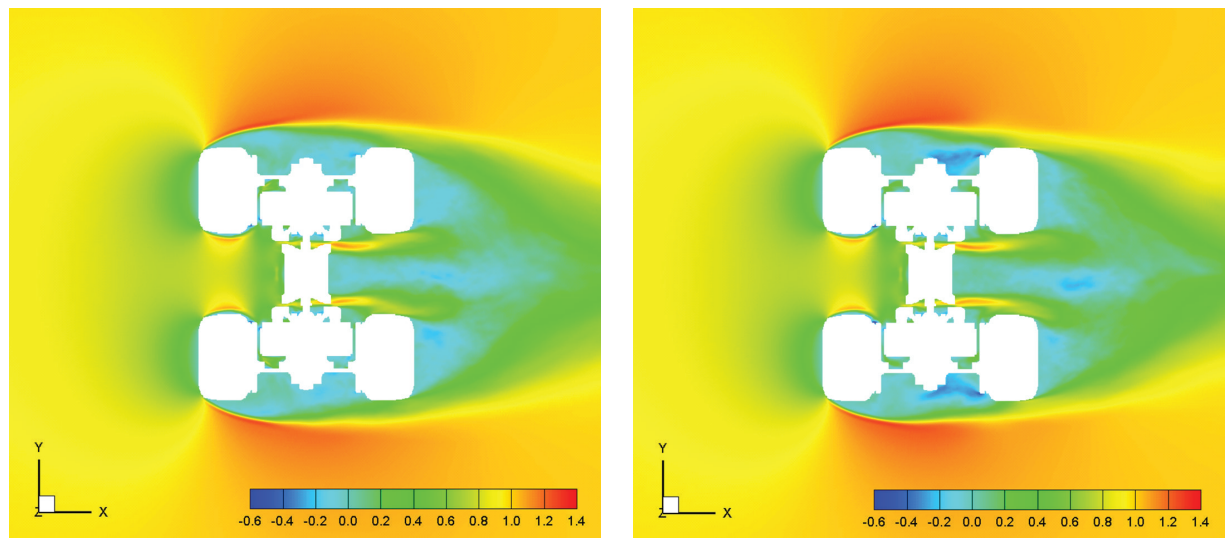

(a) Velocity component in the freestream direction
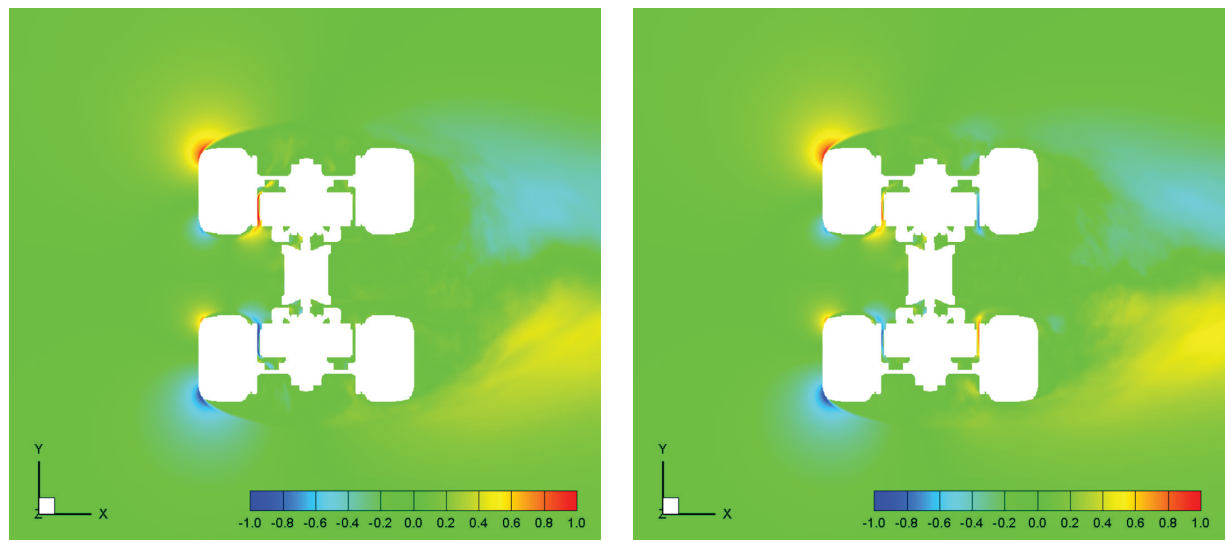

(b) Velocity component in the horizontal direction

FIGURE 20: Computed mean velocity component at cross section $z=-2.21$ (left: NO_TEAR, right: NO_SEAL).

BACK_TEAR as already described, and thus the flow does not go back to the rear axle area. On the other hand, in BACK_SEAL, the flow similarly goes inside the wheel disk region at front, but the flow goes through the disk space and finally goes back to the rear axle area as shown in Figures 18(b) and 19(b). Because of the sealed cap, the flow only goes through the internal part of the wheel and this causes the slight acceleration of flow in the freesteream direction as shown in Figures 18(a) and 19(a). This can be the reason that the BACK_SEAL shows the larger OASPL value compared to BACK_TEAR.

In the geometry without torque link, the OASPL of sealed wheel cap (NO_SEAL) is higher compared to the cap with cooling holes (NO_TEAR). Figure 20 shows the comparison of NO_TEAR and NO_SEAL at $z=-2.21$ section. The internal flow inside the wheel (brake disk region) is similar to the geometry with backward torque link, where the induced flow from inside the wheel to the outside through the holes is observed for NO_TEAR configuration but the flow is returned to the rear axle region for NO_BACK as shown in Figure 20(b). The velocity in the freestream direction is almost identical, though the circulated flow at outside of the wheel is observed at NO_SEAL as no induced flow through the sealed cap exists. In this case, the acceleration of the flow at the axle region is similar to both the geometry, but the level of OASPL is different for the wheel cap type.

The wheel cap affects the local flows of internal wheel part such as brake disk due to the induced flows through the cooling holes; however, the contribution to the noise is quite complex. The far-field noise is determined with the interaction of the induced flow with other components.

\section{Conclusion}

In this study, aerodynamic/acoustic splitting method based on Cartesian-mesh incompressible flow solver and noncompact form of Curle's equation was proposed to evaluate the far-field noise from a landing gear. The present method was first validated on a circular cylinder case, where the computation with non-compact form of Curle's equation is qualitatively in agreement with the experiment. The approach was then applied to JAXA landing gear model to evaluate the influence of torque link position and wheel cap type. The velocity component in the freestream direction of the configuration with backward torque link and cooling holes cap was reasonably in agreement with experiment and another computation. Due to the introduction of Curle's equation in non-compact form, the computed SPL levels were well matched with the experiment, whereas a large 
discrepancy was observed in the past. OASPL values were also compared with the experiment, and the tendency of the OASPL for different geometry was qualitatively captured. The velocity component of the different LEG configuration was compared, and the results showed that the torque link position had a large influence on the flow characteristics at the axle region between the two wheels and in the wake region. The torque link when in forward position prevented the acceleration of flow between the wheels, which reduced the far field noise. When the wheel cap had cooling holes, the flow induced from the inside of the wheel to the outside through the cooling holes was observed. On the other hand, when the wheel cap was sealed, the flow inside the wheel went through the internal component of brake disk space, and finally goes back to the rear part of axle region. The contribution of the wheel cap itself to the far field noise was difficult to assess as there was also interaction of the induced flow with other components. The present approach was proved to be effective in evaluating the effects of tiny detailed components attached to landing gear for the purpose of farfield aerodynamic noise prediction. Because the flows and aerodynamic noises of a landing gear are quite affected by the detail components and their interactions, a detailed model is required in future simulations and evaluations of low noise components and devices.

\section{Nomenclature}

BCM: Building-Cube Method

$c_{0}: \quad$ Speed of sound

$D: \quad$ Characteristic length

$i, j: \quad$ Index coordinates

$L_{i j}$ : Lighthill's stress tensor

LEG: JAXA Landing gear Evaluation Geometry model

OASPL: Overall sound pressure level

$P: \quad$ Static pressure on body surface

$P_{0}: \quad$ Reference sound pressure in air

$P_{a}$ : $\quad$ Sound pressure fluctuation

$P_{e}: \quad$ Effective sound pressure

$r: \quad$ Distance to observation point

Re: $\quad$ Reynolds number

S: $\quad$ Surface

SPL: $\quad$ Sound pressure level

$\mathrm{SP}_{\mathrm{rms}}$ : Sound pressure fluctuation

$t: \quad$ time

u: $\quad$ Velocity vector

$\mathrm{x}$ : Coordinates of sound observation point

y: $\quad$ Coordinates of sound source point

$V: \quad$ Volume

$\rho: \quad$ Density.

\section{Acknowledgments}

The authors sincerely thank Dr. M. Murayama, Dr. T. Imamura, and Dr. K. Yamamoto at Japan Aerospace Exploration Agency because they provided us the LEG model and experimental data. Computations in this paper were conducted by NEC SX-9 at Cyber Science Center, Tohoku University. This work was supported by JSPS KAKENHI 21226018.

\section{References}

[1] A. Keating, P. Dethioux, R. Satti et al., "Computational aeroacoustics validation and analysis of a nose landing gear," in Proceedings of the 15th AIAA/CEAS Aeroacoustics Conference, May 2009.

[2] D. P. Lockard, M. M. Choudhari, M. R. Khorrami et al., "Aeroacoustic simulations of tandem cylinders with subcritical spacing," in Proceedings of the 14th AIAA/CEAS Aeroacoustics Conference, May 2008.

[3] P. R. Spalart, M. L. Shur, M. K. Strelets, and A. K. Travin, "Reprint of: towards noise prediction for rudimentary landing gear," in Proceedings of the IUTAM Symposium on Computational Aero-Acoustics for Aircraft Noise Prediction, vol. 1, pp. 283-292, 2010.

[4] T. Imamura, T. Hirai, K. Amemiya, Y. Yokokawa, S. Enomoto, and K. Yamamoto, "Aerodynamic and aeroacoustic simulations of a two-wheel landing gear," in Proceedings of the IUTAM Symposium on Computational Aero-Acoustics for Aircraft Noise Prediction, pp. 293-302, March 2010.

[5] Y. Yokokawa, T. Imamura, H. Ura, H. Kobayashi, H. Uchida, and K. Yamamoto, "Experimental study on noise generation of a two-wheel main landing gear," in Proceedings of the 16th AIAA/CEAS Aeroacoustics Conference, June 2010.

[6] Y. Murayama, K. Yokokawa, H. Hiroyuki et al., "Computational and experimental study on noise generation from tireaxle regions of a two-wheel main landing gear experimental study on noise generation of a two-wheel Main landing gear," in Proceedings of the 17th AIAA/CEAS Aeroacoustics Conference, 2011.

[7] H. Onda, R. Sakai, D. Sasaki, and K. Nakahashi, "Unsteady flow aerodynamic noise analysis around JAXA landing gear model by building-cube method," in Proceedings of the 49th AIAA Aerospace Sciences Meeting, 2011.

[8] K. Nakahashi and L. S. Kim, "Building-cube method for largescale, high resolution flow computations," in Proceedings of the 42nd AIAA Aerospace Sciences Meeting and Exhibit, pp. 676684, January 2004.

[9] K. Nakahashi, "High-density mesh flow computations with pre-/post-data compressions," 2005.

[10] K. Nakahashi, A. Kitoh, Y. Sakurai, and M. Meinke, "Threedimensional flow computations around an airfoil by buildingcube method," in Proceedings of the 44th AIAA Aerospace Sciences Meeting, pp. 13361-13370, January 2006.

[11] S. Takahashi, T. Ishida, K. Nakahashi et al., "Study of high resolution incompressible flow simulation based on cartesian mesh," in Proceedings of the 47th AIAA Aerospace Sciences Meeting Including the New Horizons Forum and Aerospace Exposition, January 2009.

[12] S. Takahashi, Study of large scale simulation for unsteady flows, Ph.D. dissertation, Department of Aerospace Engineering, Tohoku University, Tokyo, Japan, 2009.

[13] T. Ishida, S. Takahashi, and K. Nakahashi, "Efficient and robust cartesian mesh generation for building-cube method," Journal of Computational Science and Technology, vol. 2, no. 4, pp. 435-446, 2008.

[14] N. Curle, "The influence of solid boundaries upon aerodynamics sound," Proceedings of Royal Society of London, Series A, vol. 231, pp. 505-514, 1955.

[15] T. Kawamura and K. Kuwahara, "Computation of high reynolds number flow around a circular cylinder with surface roughness," in Proceedings of AIAA 22nd Aerospace Sciences Meeting, 1984. 
[16] M. J. Lighthill, "On sound generated aerodynamically," Proceedings of Royal Society of London, Series A, vol. 211, pp. 564$587,1952$.

[17] C. Kato, Y. Takano, A. Iida, H. Fujita, and M. Ikegawa, "Numerical prediction of aerodynamic sound by Large Eddy simulation (1st Report, Aerodynamic sound radiated from two-dimensional circular cylinder)," Japan Society of Mechanical Engineers, Series B, vol. 60, no. 569, pp. 126-132, 1994 (Japanese). 

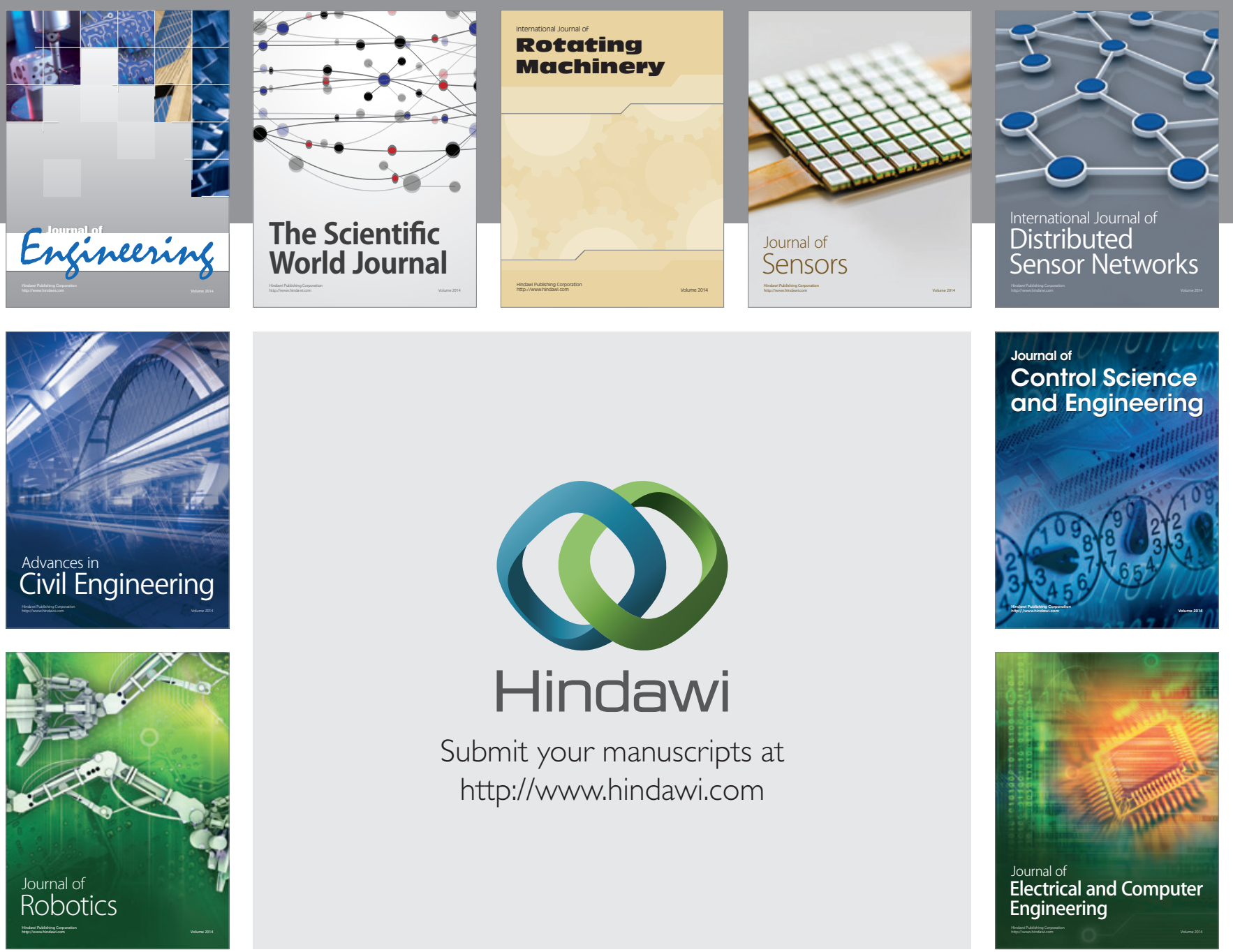

Submit your manuscripts at

http://www.hindawi.com
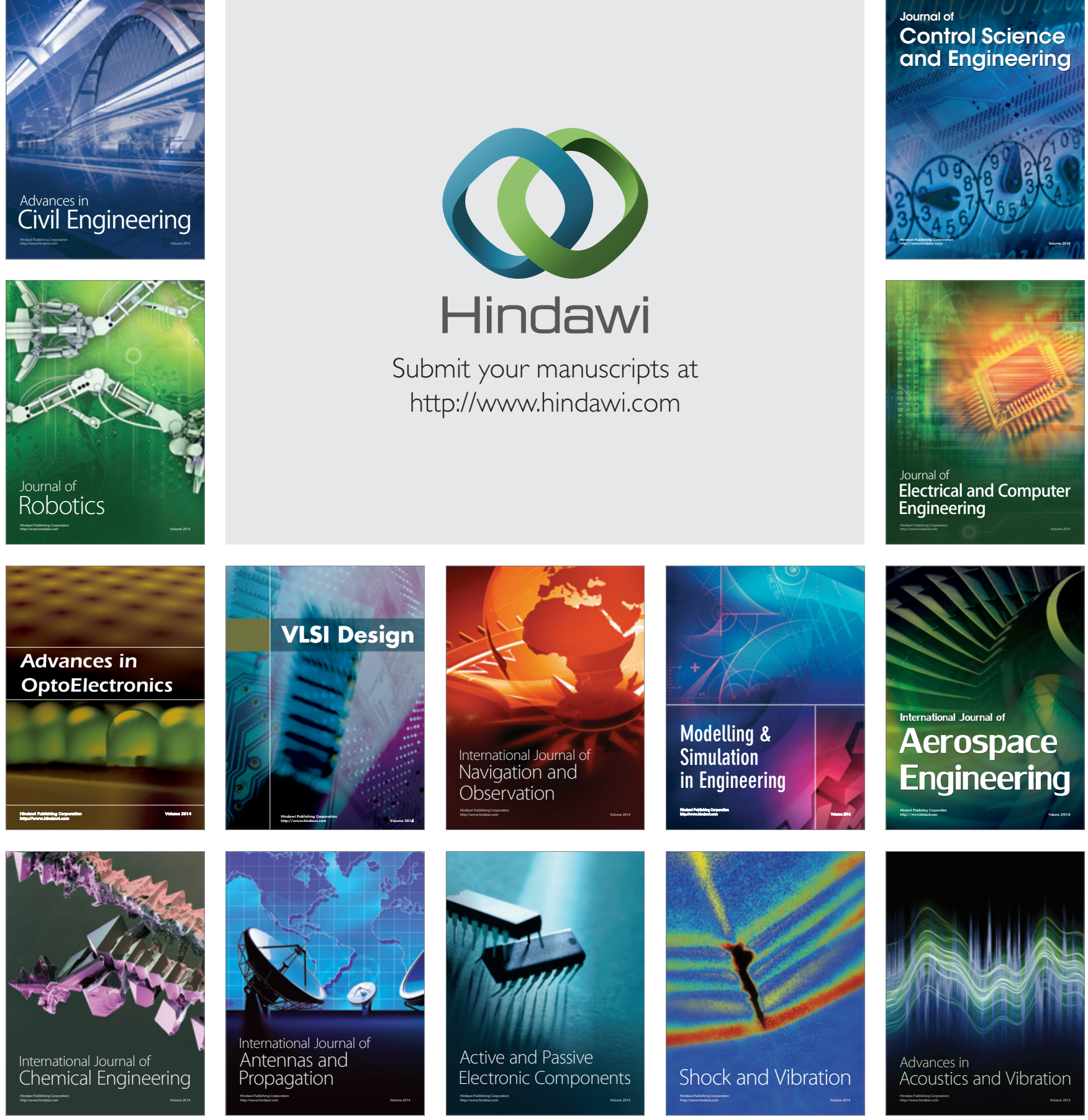